\title{
Vega, Carlos
}

\section{El canto de los trovadores en una historia integral de la música}

Revista del instituto de Investigación Musicológica "Carlos Vega"

Año 1, No 1, 1977

Este documento está disponible en la Biblioteca Digital de la Universidad Católica Argentina, repositorio institucional desarrollado por la Biblioteca Central "San Benito Abad". Su objetivo es difundir y preservar la producción intelectual de la Institución.

La Biblioteca posee la autorización del autor para su divulgación en línea.

Cómo citar el documento:

Vega, Carlos. "El canto de los trovadores en una historia integral de la música". [en línea]. Re vista del Instituto de Investigación Musicológica “Carlos Vega”, 1, 1 (1977). Disponible en:

http://bibliotecadigital.uca.edu.ar/greenstone/cgi-bin/library.cgi? $\mathrm{a}=\mathrm{d} \& \mathrm{c}=$ Revistas $\& \mathrm{~d}=$ canto-trovadores-historia-integral [Fecha de consulta:........] 


\section{Dl canto de los trouadores en una historia integral de la muisica}

Ha de haber llegado el momento de afirmar con naturalidad que la música de los estrados principescos que se encumbraron en la Edad Media tardía, hace cosa de mil años, se encuentra hasta hoy por campos de Occidente sobrellevando la vida posible a su recia vejez; pero viviendo, apta todavía para inspirar apetencias y cumplir funciones, aun capaz de obtener resonancia en los espíritus. No es difícil hallar en los ambientes folklóricos música que se difundió en fechas remotas; pero se necesita conocer la música de fechas remotas para atribuir antigüedad determinada a la que hoy nos impresiona como lejana. En términos más concretos, se necesita conocer las canciones anotadas en la Edad Media tardía; se necesita leer los ilegibles manur critos de los trovadores.

Ya saben los especialistas que muchas y muy singulares circunstancias favorables quisieron acompañarnos en la juvenil empresa de aclarar los documentos trovadorescos, y que no perdimos tan extraordinario auxilio del azar. Es el caso que en 1932 empezamos a leer aquellos manuscritos, y que al cabo de unos veinte años de labor casi incesante conseguimos poner en notación moderna miles de melodías de trovadores, troveros, spruchdichter alemanes, cantigas españolas, laudes italianas, en fin, gran parte de la música no gregoriana de los siglos XII y XIII, "la música de los trovadores", como suele llamársela para abreviar.

Las fórmulas esenciales de orientación que definieron nuestro itinerario tuvieron que enfrentar o eludir casi todas las ideas consagradas por los medievalistas más autorizados. Mucha importancia ha tenido la dominante afirmación de que el canto trovadoresco fue una creación circunscripta, exclusiva, propia de un momento y cerrada al porvenir. Se ha pensado que consistía en obras extrañas cuyo enfoque requería el abandono de toda impresión moderna.
Pierre Aubry, medievalista renombrado, escribía en 1908: "Yo diría casi que vale más olvidar lo que sabemos, hacer abstracción de nuestras ideas actuales, de nuestra formación estética, de esos prejuicios inconcientes que forman nuestra mentalidad musical, y recrearnos un estado de espíritu especial y nuevo que nos haga más aptos para comprender los principios del arte en que se han inspirado los músicos del siglo XIII" (Trouvères et troubadours, Paris, 1909, pág. 176). Antes habia escrito que era necesario dar a la notación trovadoresca "un sentido musical que por si mismo no aparece; una significación cuyo secreto se llevó el siglo que la vio nacer" (La rythmique musicale des troubadours, París, 1906, págs. 5-6). Hace más de cincuenta años que esta opinión básica de orientación influye sobre medievalistas, historiadores y docentes. Aubry aplicó un método infundado y obtuvo de los manuscritos melodías que no se parecían a las melodías modernas ni a las antiguas ni a nada $y$, en lugar de abandonar sus ideas y transcripciones, lanzó a posteriori la idea monitora de que el siglo XIII tenía su estética. Es decir, que le atribuyó al siglo $X I I I$ sus propias elucubraciones y en ellas quiso ver después una estética medieval.

Pierre Aubry, erudito notable, por lo demás, no creó su método; Jean Beck, de Estrasburgo, musicólogo no menos famoso, lo precedió en la idea de una relación rítmica entre texto y melodía y compartió con él la responsabilidad de los errores.

Otra de las opiniones dominantes hasta hoy difunde que los modos gregorianos presiden toda o parte de la creación trovadoresca $o$, por lo menos, que hay escalas hibridas. Siempre ha impresionado el hecho de que el canto de los trovadores se haya escrito con signos gregorianos, y un autor afirmó que toda esa música es gregoriana simplemente porque está escrita con signos eclesiásticos. Como si hubiera una nota- 
ción para cada música. Se llegó a decir de alguna importante colección trovadoresca que contiene "himnos religiosos". En este caso interviene la sobrevaloración histórica del canto gregoriano y la subestimación o el olvido de la música profana para danzas y canciones de altos estrados, de burgos y de campos. Jean Beck escribía en 1928: "hemos podido constatar las muy estrechas relaciones que existen entre las melodías de los trovadores y la música religiosa de la Edad Media".

Una tercera opinión sumamente nociva se interpone entre la erudición y la solución: la que atribuye a la música trovadoresca series de fórmulas rítmicas helénicas $o$, más precisamente, los modos rítmicos y los ordos medievales. La música profana obedece a otras formas y normas antiguas y posteriores, bien que un par de constelaciones coinciden con otras tantas que usaron los griegos, y también con algún ordo de la época. Los "modos rítmicos" esperaron vanamente una interpretación crítica. En su lugar los transcriptores modernos superpusieron algunas fórmulas modales rítmicas a la acentuación de las sílabas, de manera que la grafía fue enriquecida con una doble indicación del ritmo cuando en realidad no tielle ninguna. La notación trovadoresca se funda en la gregoriana y en la polifónica, pero difiere de ellas en muchas cosas importantes.

Por lo demás, era necesario entender que, en cuanto el movimiento de los trovadores se extendió desde 1100 hasta 1300 , más o menos, la notación pasó de los signos sin valor a la escritura medida. Ha sido error difundido la atribución de medida a las notas que no la tienen y la negación de valor a las figuras valoradas.

Admitamos ahora que la insuficiencia de la notación trovadoresca es la causa directa y real de la incertidumbre y los errores; pero no olvidemos que los teóricos medievales dijeron todo lo necesario para que nadie atribuyera duraciones a las notas por la acentuación de las sílabas, para que nadie supusiera modos gregorianos, para que nadie siguiera al pie de la letra las indicaciones sobre los ritmos de la polifonía.

Ningún musicólogo ha podido comprender los manuscritos de música profana de los siglos XII y XIII y leerlos cabalmente. Algunos transcribieron bien -si no se equivocaron en la tonalidad- algunas de las pocas melodías académicas que a última hora se escribieron con longas y breves.
Estas nunca presentaron dificultad; pero la enorme masa de canciones que se ha conservado en notación sin medida jamás fue conmovida por una visión certera. Hace muchos años que las más grandes autoridades de Occidente coinciden en negar los resultados de todos los transcriptores. No está de más que oigamos sus afirmaciones. Jules Combarieu nos dice, aludiendo a la discrepancia de los transcriptores: "una cuestión tan diversamente resuelia por arqueólogos de gran autoridad muestra que es todavía imposible dar una interpretación exacta de la lírica de los trovadores y troveros" (Histoire de la musique, París, 1930, pág. 339). Théodore Gérold, medievalista eminente: "Pero las monodias habían sido muy descuidadas; los ensayos de transcripción han tenido un carácter más bien engañoso"... "los resultados han sido negativos". (La musique au Moyen Age, París, 1932, pág. 92). Gustave Reese, erudito norteamericano: "Muchas cuestiones concernientes a la interpretación rítmica están todavía abiertas a discusión" (Music in the Middle Ages, New York, 1940, pág. 210) . Jacques Chailley, autoridad europea: "No obstante las seductoras teorías de Beck y Aubry sobre los principios rítmicos que permiten leer la música de todos estos poetas compositores"... "demasiada incertidumbre subsiste todavía sobre la transcripción a proponer en notación moderna" (Histoire musicale du Moyen Age, París, 1950, pág. 138).

Si realmente es así, como se cree, como creemos nosotros, eran distintos los caminos directos. Nos iniciamos con la observación de que la música de los trovadores no ha muerto y que, aunque débil, se encuentra a nuestro alrededor. Pero esta idea, que un visionario genial lanzó antes que nosotros, no habría bastado. Nosotros introdujimos al esfuerzo total un estudio exhaustivo de las formas de las ideas musicales y esto, precisa y casi exclusivamente esto, es lo que determina y explica nuestra penetración en los secretos de los manuscritos medievales. Hubo leyes de forma $y$ eran de todos conocidas o intuídas; por eso no se escribieron.

Se necesita además creer con fe entera que la música puede vivir mil años en los cauces de la tradición oral, aun fuera de su contorno original; y para eso era prec1so desdeñar aceptados conceptos de la sociología moderna sobre integración obligatoria y admitir que la música -por lo 
menos la música- puede reclamar un tratamiento excepcional, en cuanto parece evidente que sobrevive a "su época". También se requería la introducción personal del musicólogo en esos cauces tradicionales, la colección de la música folklórica en gran escala y el estudio metódico de sus estructuras. De esa fe, de tal desdén, de la colección y del estudio han dado amplia cuenta varios libros nuestros. (Recuérdese que hemos hecho unos 35 viajes de estudio por la Argentina y por parte de Sudamérica y que hemos grabado más de 5.000 melodías folklóricas).

Toda la historia general de la cultura funda su capítulo sobre Prehistoria en la certeza de que existen casos de pervivencia extraordinariamente dilatados. No mil años; decenas de miles de años - por no decir centenares de miles- han sido atravesados por diversos bienes espirituales y materiales en manos de sus primitivos usuarios. Los comienzos de la música humana están vivos en la voz de las tribus más rezagadas.

La limitadísima perspectiva histórica en que se han producido y producen los estudios musicales de conservatorio ha impedido ver el pasado como un territorio surcado por mil torrentes de música que desembocan en nuestros días por todas partes. Baste con recordar la difundida y escasa fórmula de los historiadores: primero, la melopea griega; segundo, la melopea cristiana; tercero, la polifonía medieval y cuarto, la armonía moderna. Cuatro venerables monumentos, cuatro floraciones de reducidísimas minorías superiores y un olvido total de las innumerables corrientes multitudinarias que la tensión emocional de los pueblos ha vitalizado y sostenido hasta hoy en todo tiempo y lugar. Hace siete $u$ ocho siglos que la incipiente notación diastemática occidental aprehendió un momento lúcido de esas corrientes antiguas. Medio centenar de infolios documentan la hazaña primera y crean severo problena al intérprete moderno.
En estas breves páginas no se trata de recordar, ni siquiera en prieta síntesis, las peripecias intelectuales de una veintena de años ante los manuscritos medievales: la revisión de la bibliografía moderna, el estudio de los teóricos coetáneos, el examen paleográfico, el análisis de los signos, la delimitación de los diversos sistemas, el hallazgo de las claves de escritura, las verda deras relaciones de la música con el texto, el estudio comparado de los códices, el descubrimiento de los esiilos medievales... No; un libro de mil quinientas páginas y mil clisés espera disponible tiempo nuestro para la imprenta. Deseamos ofrecer en esta oportunidad nada más que una primera noticia sobre analogías estilísticas entre las melodías de los trovadores y los diversos cancioneros folklóricos americanos. Y llamamos la atención sobre una exigente pretensión nuestra: que esas relaciones son, por sí mismas, la prueba definitiva de que nuestra lectura de los manuscritos medievales es la exacta, es decir, la única exacta. A pesar de sus anuncios, ningún medievalista moderno ha presentado paralelos concretos entre sus versiones y las de cualquier música actual; y es claro que tal divorcio o desencuentro supondría, por una parte, un gran movimiento medieval sin descendencia - cosa imposible-, y por la otra, grandes estratos de música folklórica, antigua por definición, sin ascendencia, cosa imposible.

Antes de presentar los prometidos paralelos queremos decir algunas palabras sobre la rítmica y la tonalidad de los trovadores. Nuestro recordado estudio exhaustivo de las formas de las ideas musicales opera sobre el hecho de que en el mundo de la música antigua nada está librado al albedrío del creador. Hay un corto número de formas preferidas. La simetría es un principio sicológico que impone sujeción a estructuras regulares. El estudio de los códices medievales revela que las melodías de los trovadores se producen casi exclusivamente en las cuatro formas siguientes (fórmulas básicas) :
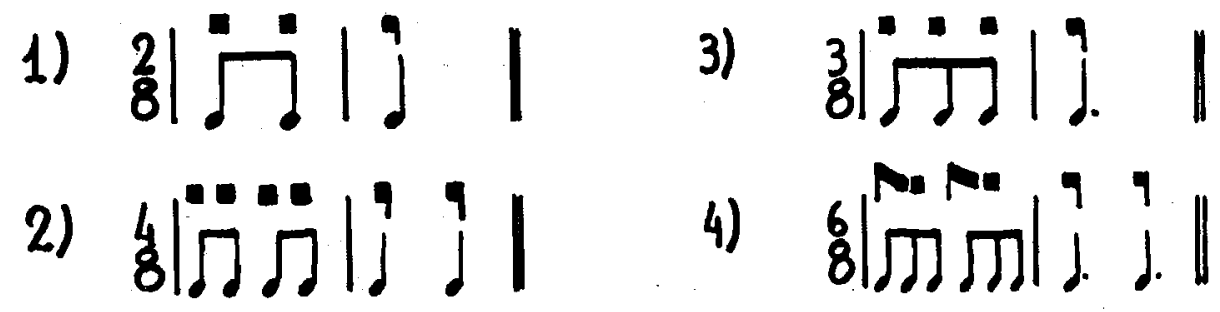
Aclaraciones: utilizamos solamente la serie del 8 (la corchea como unidad) y sobre esta uniformidad publicamos extensa obra; [Vega, Carlos, La música popular argentina. Fraseologia, 2 vols., Bs. As., 1941]; si el lector tiene ideas perturbadoras con respecto a las cifras del compás, puede sacar éstas o poner en su lugar las que le son familiares; si la perturbación se relaciona con las líneas divisorias, puede sacarlas también, pues nos conformamos con que deje las alturas y las duraciones; las cuatro formas del ejemplo representan las numerosas fórmulas distintas que pueden articularse si se cambian los valores dentro de cada pie (subdivisiones, puntillos, etc.), sin que se modifique el valor total del compás.

Cuando un largo estudio de manuscritos nos enfrentó con melodías del siglo XIII escritas en notación medida, quedó definitivamente establecido, por testimonio expreso de los propios ananuenses medievales, que las formas atribuídas por nosotros a aquellas antiguas canciones eran precisamente las formas de los trovadores. Son las del cuadro, excepto la primera $(2 \times 8)$, rarísima; sólo aparecen tres o cuatro por mil, que nunca han sido/escritas en notación medida. Lo cual no significa negación de su existencia.

En cuanto a la tonalidad, las melodías de los trovadores revelan, principalmente, las siguientes gamas: una escala hexatónica menor con sensible "abajo"; las escalas llamadas menor armónica y menor melódica, especialmente activas en la sección plagal (plagal profano); la escala llamada "modo mayor moderno"; la combinación orgánica del mayor con los menores; la fusión de dos escalas menores ensambladas, con una tónica en "su lugar" y otra tónica una cuarta abajo; formaciones híbridas; esquemas pentatónicos.

Tan ricas eran las disponibilidades tonales de los trovadores; tan complicadas para aquellos teóricos simplistas de los ocho modos antiguos, que ninguno acertó a imaginar ese complejo mundo tonal que integraban tantas escalas extrañas para ellos. Ante la evidencia de intervalos desconocidos, e incapaces de entenderlos como secciones de otras gamas, dieron en explicarlos como alteraciones, es decir, como adulteraciones de los modos antiguos. Sólo dos o tres tratadistas llegaron a intuir que la música profana respondía a gradaciones no gregorianas, así, negativamente, sin alcanzar a representarse las diversas gamas civiles. Johan- nes de Grocheo, inesperado ensayista cuyo singular tratado ilumina la Europa musical del siglo XIII, escribe refiriéndose a la música ciudadana (simplici musica vel civil, quem vulgarem): "Este canto justamente no va por reglas del tono ni por ellas se mide"; y lo repite en otros términos igualmente inequívocos. El Anónimo II de Coussemaker y Johannis Gallicus confirman esta observación. Hubo varios criterios, de aparición sucesiva y aplicación simultánea, para sortear las grandes dificultades de anotar la "nueva música".

Uno de ellos se funda en el reconocimiento de las escalas menores por analogía con los modos eclesiásticos que tienen tercera menor, y se generaliza una técnica que consiste -creemos haberlo visto por vez primera- en reservar sus tónicas para los menores: los menores, pues, se escriben en la, re y sol; por lo tanto, los mayores, en do, en fa y (con becuadro en fa o sin becuadro) en sol. En concordancia con esta práctica los teóricos preceptuaron reiteradamente que en las fórmulas la-sol-la, re-do-re y sol-fa-sol, la nota central estaba a distancia de semitono, es decir, indicaban las sensibles de los menores. Basta con tales preceptos -digámoslo de paso- para rechazar todas las transcripciones que omiten las sensibles de los menores; y añadamos que aún en la misma época de los trovadores se escribieron melodías con la alteración de la sensible.

Otro de los criterios coetáneos tornabá innecesaria la escritura de las alteraciones. Supongamos que nosotros, en lugar de montar la armadura, ponemos una breve aclaración que diga, por ejemplo, "fa mayor" o "do menor"; bastaría con esto para que imagináramos las alteraciones, como en el actual transporte mental. Recordemos ahora que la tónica medieval establecía por sí misma el carácter mayor o menor de la escala profana y admitiremos que el lector de la época podía reproducir los intervalos de la escala extra-teórica por simple conocimiento práctico de los giros, ya que no por una coincidencia plena de la escala misma. Es esto lo que nosotros llamamos la aplicación de "patrones mentales" (las escalas -como suma de giros- pensadas como complemento de la notaciôn defectiva).

Un tercer criterio medieval aspira a modificar gráficamen'e los patrones mentales gregorianos implícitos en las tónicas modales. Las líneas y espacios de la pauta no 
indican de manera alguna los intervalos de semitono. Los patrones mentales de los modos gregorianos y del modo mayor moderno determinan los semitonos de si-do y de mi$\mathrm{fa}$, no por la grafía, sino por enseñanza oral. El fa gregoriano tiene el si natural por obra del patrón mental eclesiástico, el bemol de si destruye el patrón mental gre goriano e instituye gráficamente el mayor moderno sobre la tónica Fa. Pero este criterio tardó quinientos años en comprender integralmente el problema e imponerse, de manera que a lo largo de todo ese tiempo el uso de las alteraciones careció de regularidad. Todavía en 1724 Fray Pablo Nassarre advertía a los cantollanistas "que en el Canto llano, por maravilla se señala el bemol, assi natural, como accidental"... Y recomienda que -en sus casos- lo hagan aunque no esté señalado. Es de imaginar lo que ocurriría en la notación profana. Todas las escalas mundanas actuales y otras que se perdieron funcionaban plenamente en el siglo XIII, como era de esperar.

Pasemos ahora a la prueba de las supervivencias. Aun cuando nuestro libro sobre los trovadores explicará a su tiempo, paso a paso, el proceso de nuestro método en el orden ideográfico, nosotros creemos -lo repetimos-que nuestros paralelos entre las canciones medievales y las folklóricas actuales son suficientes para inspirar, por lo menos, un franco asentimiento provisional. No es pobre argumento que estas viejas expresiones formales y estilísticas coincidan con las que necesitábamos para explicar el origen de otras tantas expresiones formales y estilísticas que se encuentran en el ambiente folklórico sin antecedentes conocidos. Y añadamos que, contra lo que podía sospecharse, la grafía de la tonalidad -en parte aclarada por preceptos teóricos complementarios- y la grafía de la rítmica - con signos de fraseo y hasta claves numerales-, si bien podrían permitir a veces un escaso margen interpretativo para variantes, en modo alguno autorizarían la libertad total que se necesita para crear formas y estilos al gusto de cada uno. Porque si así fuera esa escritura no habría sido escritura ni nada en los tiempos mismos de los trovadores. Sólo podrían hablar hoy de arbitrariedades los que están fuera de las intimidades paleográficas.

El tiempo que ha transcurrido desde los trovadores hasta el folklore actual es grande. Para que no lo sea tanto, podríamos empezar por ofrecer algunas muestras de subsistencia de formas y estilos medievales profanos en melodías del siglo XVI, es decir, a medio camino. Gran parte de la música culta y media no polifónica está salpicada de temas trovadorescos a lo largo de todos los siglos intermedios. Su descenso a las clases rurales -es ley sociológicaexplica su persistencia en los hon:anares folklóricos.

Veamos primero una canción española del siglo XIII escrita en notación mensural pura -excepto la mínima prolongación de
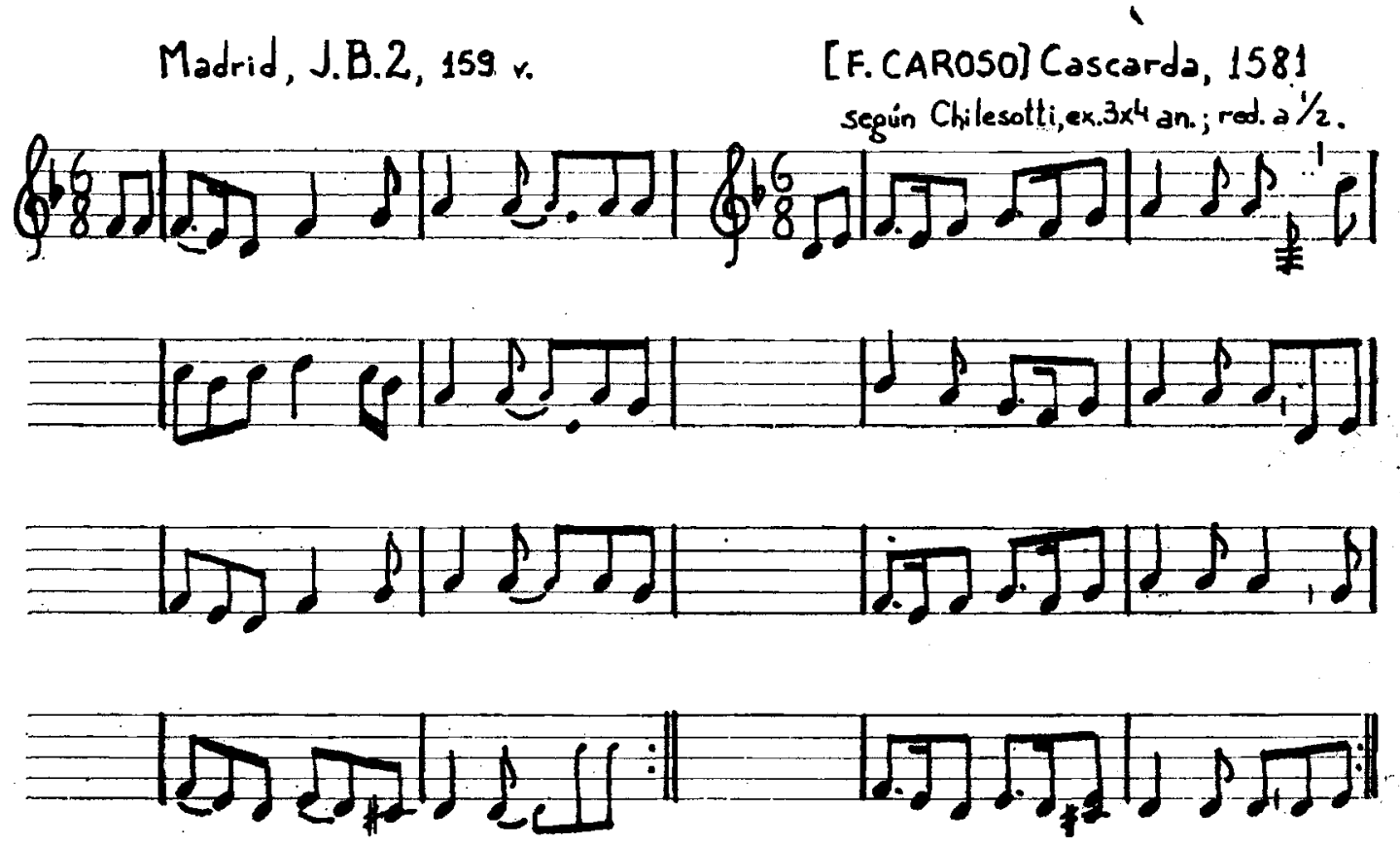
fin de frase (nota chica) por la regla de mora ultimae vocis- $\mathrm{y}$ observemos cómo perduran sus giros en una cascarda de 1581, y cómo las notas inmediatas a las líneas divisorias son todas iguales, al extremo de que necesitamos admitir que ésta es una variante de aquélla.

Este paralelo solo, a base de una transcripción nuestra no hipotética sino indiscutible, rompe el supuesto círculo cerrado de la Edad Media y nos muestra el desborde de los trovadores sobre los siglos in- mediatos siguientes en el nivel de la "mesomúsica".

Examinemos ahora una canción francesa del siglo XIII y comparémosla con un período temático del "Balletto detto Il conte Orlando", del siglo XVI. Demos una transcripción "libre" (!) de Ottorino Respighi (en Antiche Danze ed Arie por Liuto, Ricordi, s/f.) y lamentamos no haber podido consultar el original antiguo para ver qué significa esa libertad. Por lo pronto, con libertad y todo, véase lo que ocurre, ambas a la vista:

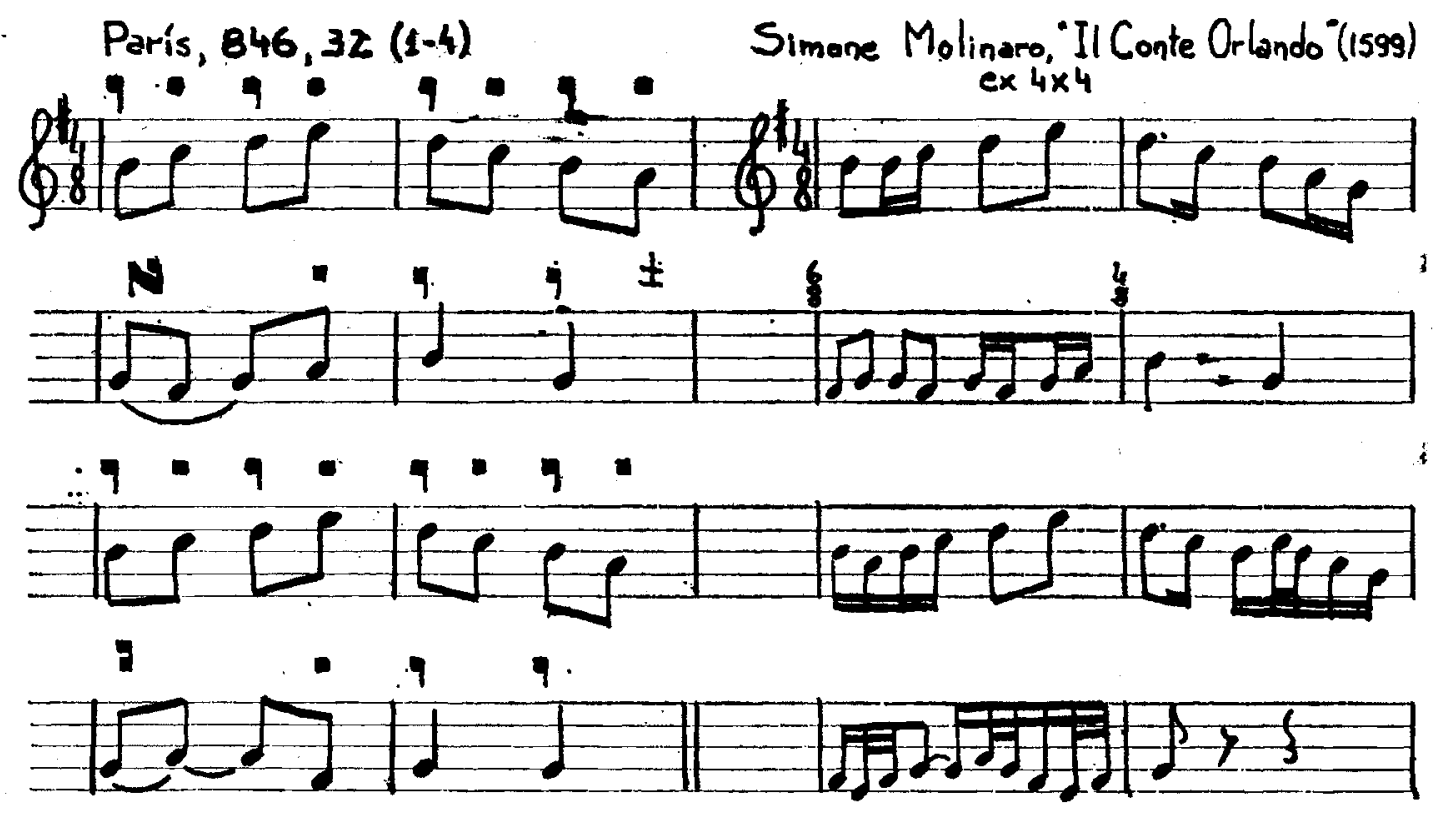

Una libertad de origen ignorado se manifiesta en dos sentidos: contra el llano y delicado estilo de la versión medièval, el balletto introduce pasajes ornamentales que, sin embargo, no abandonan la línea antigua; contra la rigurosa simetría trovadoresca, el balletto nos muestra una segunda frase estirada, de tres pies, ilógica, fuera de medida, no sabemos por obra de qué mano. Ni nos interesa. Lo inevitable es que la compleja melodía del trovero francés es el modelo que resuena en el balletto de 1599.

El caso de la transcripción nuestra nos obliga a ofrecer aclaraciones no previstas en nuestrø planteo. Poco antes y después de 1300 hubo un momento de confusión. La escritura de pies binarios -que se usaba a más y mejor al lado de los supuesta. mente exclusivos pies ternarios- se hacía también con longa-breve. Marchetto de $\mathrm{Pa}$ - dua escribía a comienzos del siglo XIV que el binario y el ternario "del mismo modo se figuran" (et eodem modo configurântur; Coussemaker, III, pág. 5). Parece increíble, pero Marchetto nos da la tranquilizadora razón de esa igualdad: "porque de lo imperfecto nunca puede haber ciencia material" (Quia de imperfectis nunquam potest esse scientia materialis). Esto es, que el orden binario no se puede escribir. Nosotros lo transcribimos en binario por el podatus que, dicho sea de paso, es $^{+}$á muy bien si se lo valora polifónicamente (breve-longa), pero que en el orden profano constituye un recurso forzado $c$ irregular.

La eficacia de la prueba comparativa no consiste en estos pocos paralelos ni en los que se encuentren mañana, por suficientes que parezcan. Acabamos de dar coincidencias de temas y estructuras y daremos hasta 
un singular caso de identidad casi total de la canción entera. Todos veremos que son pruebas irrecusables; pero no es eso lo que nos importa. Al contrario, estos episodios analógicos, si no abundan, pueden atraer la idea de exigir muchos que, además, sean idénticos. No. Queremos orientar el enfoque y llamar la atención sobre la coincidencia de los estilos medievales con los históricos o los folklóricos.

En sus etapas creadoras los pueblos elaboran "estilos". Los estilos no se definen solamente por una escala o por un grupo de escalas particulares, ni por una forma o más formas rítmicas; se definen por el uso de una selección de células o giros melódicos y por un modo de tratarlos; por una selección de células y de fórmulas rítmicas; por el empleo de un corto número de cadencias (comúnmente parte o toda la última frase de cada período); por maneras de ejecución, etc. De modo que el creador y su grupo social se satisfacen con un relativamente limitado número de las innumerables combinaciones de-elementos que pueden ofrecer las alturas, las duraciones y la paleta de la expresión. Por esto mismo también son innumerables los "estilos" y, cuando reaparecen, cẹrca o a gran distancia en el tiempo o en el espacio, el origen común es evidente. Nosotros creemos en la imposibilidad de que dos movimientôs creadoress, cada cual por su lado, produzcan estilos iguales; siempre entendiendo que el "estilo" significa pluralidad, es decir, que debe consistir en un número de canciones proporcionado con la densidad de los grupos sociales usuarios; pero, en determinadas circunstancias, una sola y única melodía de fuerte originalidad puede presuponer contorno estilístico y cantidad. En la comparación de "estilos" se da la quitaesencia del "criterio de cantidad" que preconiza la metodología etnológica.

No es lo más común que el creador de cada melodía acumule en ella "todas" las características de su estilo. Si una canción contiene parte de esos caracteres, y una segunda canción otros distintos - caso extremo-, puede ocurrir que, sin coincidir en un solo valor, en un solo giro, las dos canciones pertenezcan a la misma familia estilística a través de melodías parcialmente afines. Los paralelos que ofrecemos tienen - repetimos- gran poder demostrativo por sí mismos, pero es mayor todavía la fuerza probatoria de la analogía del estilo que se nos revela en ellas y que, en rigor, se superpone a la analogía particular de las dos canciones comparadas.

Nuestra labor de transcripción reveló un insospechado número de estilos vigentes en la etapa trovadoresca (1100-1300) y todos ellos tienen correspondencia en igual número de estilos actuales, ya en el ambiente de la "mesomúsica", ya en los terrenos folklóricos. Además, aparecieron en los manuscritos medievales los estilos escogidos por los compositores de los círculos encumbrados para fundar la música superior de Occidente. El llamado "criterio de cantidad" por los etnólogos alemanes no es un segundo criterio al lado del "criterio de forma" sino la reiteración de la analogía formal en varias especies de las que integran agrupaciones de hechos culturales. Esencialmente, siempre se trata del "criterio de forma". La multiplicidad dentro de la especie musical supone que cada melodía es un producto que no se repite; en el cotejo de estilos - cotejo de subespeciesse comparan cantidades.

Nosotros sostenemos que los acompañàmientos armónicos en fórmulas breves que la historia no explica, están activos en la Edad Media, y que acaso vengan de épocas muy anteriores. Nos referimos a esos esquemas regulares (de "un compás", diríamos) que hoy oímos en el vals, la polca, la habanera, la mazurca, la marcha, etc., - de todos conocidos-, y en numerosas especies líricas y coreográficas folklóricas. Esas fórmulas son elementos fuertemente caracterizadores desde su secundario plano acompañante y en cuanto se presentan asociadas con diversos estilos melódicos llegan a constituir verdaderas "familias de estilos". Con frecuencia ocurre que las fórmulas rítmicas fijas del acompañamiento se reflejan o resuenan en la línea melódica, y hasta podría pensarse que al comienzo las melodías mismas respondían al esquema acompañante; hoy es común que se introduzcan variantes tanto en el esquema como en la línea melódica.

A lo largo de las costas del Atlántico, desde Norteamérica hasta la Argentina, vive un cancionero rural y suburbano de humilde factura, carácter penetrante y gran éxito social. Varias veces ha ascendido al plano superior de la "mesomúsica" con los nombres de ondú, modiña (binaria), samba, danza, entre otros muchos, y se ha colocado en los programas universales del baile con los nombres de habanera, maxixe, tango argentino, y con el de algunas danzas norteamericanas. Este cancionero-que 
al lado de su estilo principal admite otros y forma un grupo de estilos - tiene una sola forma de frase (la del $4 \times 8$ ), una sola forma de período y una sola especie que cambia de nombre. Le atribuyen origen africano. Se encuentran en un manuscrito español del siglo XIII varias muestras, sin duda de ascendientes o de familiares de las americanas. Como una de esas canciones progenitoras aparece escrita en notación mensural pura -prodigio no igualado en la Edad Media - no hay nada que poner en duda. Aquí eludimos el detalle de la "longa con puntillo" por ser larga la explicación. Vamos a poner a su lado una de las melodias folklóricas americanas de la misma familia.

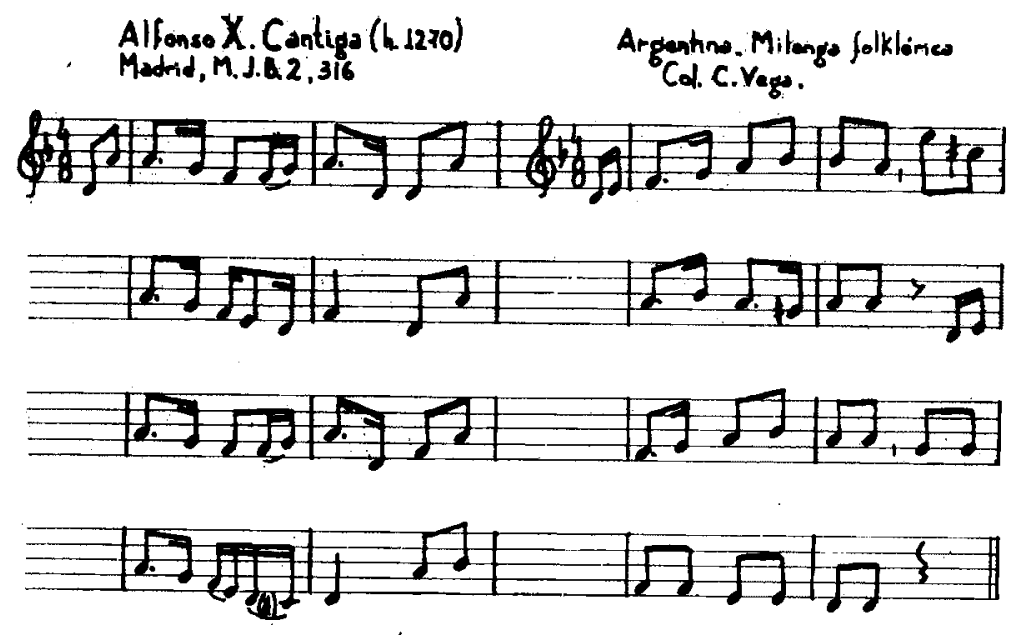

En este paralelo, como se ve, no hemos buscado la analogía de los giros mismos sino el círculo de constelaciones rítmicas características de la familia que se funda en la fórmula del acompañamiento antiguo. Esta familia rítmica domina una gran parte o la mayor parte de las expresiones del pie binario. Desapareció casi por completo en Europa pero la representan millares de canciones folklóricas y de salón vivientes hoy en cualquier lugar de América occidental. Le hacia falta su antecedente medieval y ya lo tiene.

En la ciudad de Lima, ex metrópoli colonial sudamericana y gran centro de radiación, y en toda la zona de su antigua influencia, prosperó en los siglos XVIII y XIX una familia de especies líricas de estilo análogo y seguro parentesco. Las especies recibieron en tales o cuales regiones los nombres de yaraví, triste, décima, tonada, tono y "estilo", curioso bautismo este último que nos acerca a la confusión. Se llama "estilo" precisamente por un reconocimiento de carácter. Estas especies, por mezcla con elementos aborígenes y por evolución dispar en su expansión continental, se han distanciado un poco entre sí, y ocurre que, entre todas, son las canciones llamadas "estilos" las que más directa y cabalmente permiten reconocer sus antecedentes de forma y carácter en los repertorios medievales. Una decena de "estilos" hemos hallado hasta hoy, todos en el manuscrito 846 de París; muchos centenares he grabado personalmente en la campaña argentina. No puedo ofrecer en paralelo canciones idénticas; pero una sola muestra bastará para reconocer el parentesco estilístico de las medievales con las argentinas: 

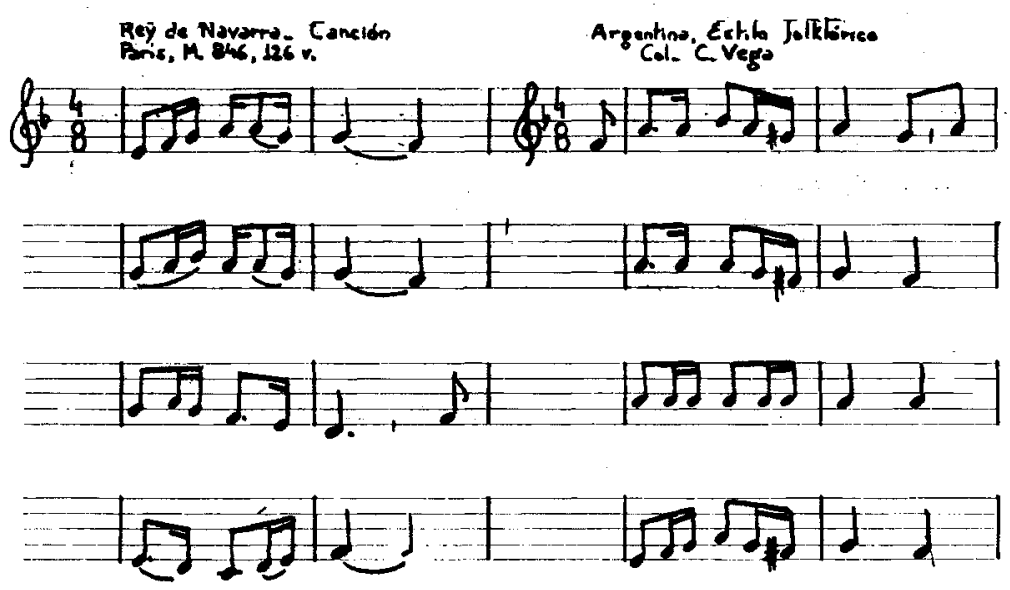

Compárese la primera frase de la medieval con la última de la argentina; pero entiéndase que no llamamos la atención sobre la semejanza de ambas sino sobre la analogía estilística. Cosa verdaderamente notable es que todas estas lejanas precursoras de los "estilos" criollos, están escritas en la tonalidad de mi menor, que jamás se usa para otras especies. Esto significaría que el amanuense define el género por la elección de la tonalidad, es decir, que se trataría de un complemento de la notación como el que reserva determinadas tónicas para los modos menores o para los mayores, como vimos. Las melodías medievales "auténticas" terminan en la tónica, salvo los pocos casos en que concluyen en la dominante para recomenzar. Todos los "esti. los" medievales no terminan en la tónica, sino en la tercera, simplemente porque la línea melódica lleva una tercera paralela inferior que está destinada a dar la tónica final, exactamente como en los "estilos" folklóricos sudamericanos. Por excepción, e] "estilo" del Rey de Navarra está escrito en re menor, esto es, que el amanuense -acaso por no haber reconocido su carácter- ha aplicado aquí la norma del re para los menores; pero, caso único, este mismo "estilo" se encuentra en el folio 82 transcripto a su tonalidad de elección, la de mi menor. Aclaremos que, otra vez como en el caso de los "estilos" criollos, el género se produce en la doble modalidad menormayor (si menor-sol mayor) y alguna vez el último período termina en la tónica del mayor.

Estos trabajos de exhumación y comparación nos revelan por vez primera la existencia de un gran cancionero que, adscripto de hecho al rito cristiano, corre por la Edad Media a un nivel semiculto o popular, en tanto la música gregoriana mantiene su plano erudito superior y oficial. Las melodías de ese cancionero apàrecen en varios códices europeos antiguos, muchas veces con texto profano; pero sus relaciones con la devoción se nos manifiestan especialmente en las colecciones de "laude" medievales, en las "lodi spirituali" del Renacimiento, y esto es lo extraordinario- en la práctica viva rural de América. Las mismas melodías de la Edad Media funcionan aquí como himnos (alabanzas, salves, trisagios, etc.), como villancicos de Navidad y -por el nexo del "niño"- como canciones de cuna.

La extensión limitada de este capítulo nos obliga a reducir los ejemplos musicales al extremo. Vamos a elegir una melodía particularmente fecunda en sugestiones de diverso orden. La notación en que se nos presenta carece por completo de toda indicación tonal (salvo la clave) y de toda aclaración sobre las duraciones. Casi la totalidad de las siete mil canciones de la época nos llegan en tan penosas condiciones. Estas han constituido siempre lo más grave del problema paleográfico. Ya hemos dicho que no hay espacio aquí ni para la más sumaria razón de nuestro método; pero ahora nos brinda la ocasión de valorar uno de los criterios auxiliares de la transcripción. Es un criterio de incidencia muy compleja, en parte activo como orientador, en parte confirmativo del resultado; cosa delicada en que hay' que eludir la petición de principio.

Nosotros hemos grabado en campaña centenares de estas canciones; este conocimiento es uno de los medios con que llegamos al manuscrito medieval, y si es verdad que por momentos ayuda, en ningún caso decide por sí mismo. Los otros criterios son los determinantes. Observemos la copia o 
calco del original. La nota final es fa, luego la tonalidad es Fa mayor (por lo que explicamos antes). Las diversas pruebas para descubrir la estructura indican que el ajuste cabal se produce en el molde de la segunda forma $(4 \times 8)$, en que una dipodia binaria se mueve y otra reposa. Nuestra grafía requiere el "compás" moderno que le conviene, el de $4 \times 8$ de nuestra nomenclatura o el $2 \times 4$ de la tradicional. El manuscrito, mediante el "finis punctorum", especie de línea divisoria con sentido ideográfico, nos indica el término del semiperíodo -nueve figuras para cada uno--, es decir que cada frase debe tener cuatro o cinco figuras. Una vez más decimos que es imposible comunicar pormenores de nuestro método. Pero, una sola vez, para que se aprecie la naturaleza del recurso y la responsabilidad técnica y crítica que significa, vamos a comunicar uno de los medios que empleamos para la determinación de las duraciones dentro de cada frase. La frase inicial, idéntica, o ligeramente variada, aparece en melodias de los siguientes códices y folios: Paris 846 , fo 3; Paris, 22543, fo $87 \mathrm{v}$, y fo 5 v; Jena fo 18 y fo 38 ; Cortona 91 , fo $90 \mathrm{v}$; Madrid, 10.069 (números de la edición de la Real Academia Española) : 17, 56, 76, 80, 92, 95; Madrid, jb2: folios 7, 40, 45, 49, 57, $62 \mathrm{v}, 75$,
$85,89 v, 90 v, 111,116 \mathrm{v}, 120 \mathrm{v}, 125 \mathrm{v} ; 130$, $131,164,153,176 \mathrm{v}, 180,182 \mathrm{v}, 185,201$ v, $209 \mathrm{v}, 214,259,263,269 \mathrm{v}, 277,278$, 280 v, 308, 308 v, 310 v, 321, 321 v, 333 v, 340 y 355 . E importa saber que esa frase inicial, la cual, por otra parte, es un tercer modo rítmico "binario" que aún reproduce la clásica constelación del dáctilo, aparece muchas veces escrita con notas medidas. Varios otros criterios integran la suma metodológica que hemos creado, y su aplicación reduce al mínimo humano las posibilidades de una falla. En todo caso, algunas incertidumbres de detalle, sin valor en el conjunto, pesan hoy ni más ni menos que como debieron pesar a los propios lectores medievales. Esta notación carecía de elementos para registrar minucias rítmicas dentro del pie de notas simples; pero el lector de la época podía optar en armonía con sus experiencias tradicionales y ese juego de pequeñas variantes pódicas era connatural a la expresión individual. Los cantantes de hoy superan aquellas libertades por sobre una escritura más estricta.

Hemos dicho mucho más de lo que nos propusimos. La elocuencia del cuadro que ofrecemos dirá, a un lado pormenores de transcripción, mucho de lo que nos importa sobre los antecedentes medievales de la música folklórica americana.

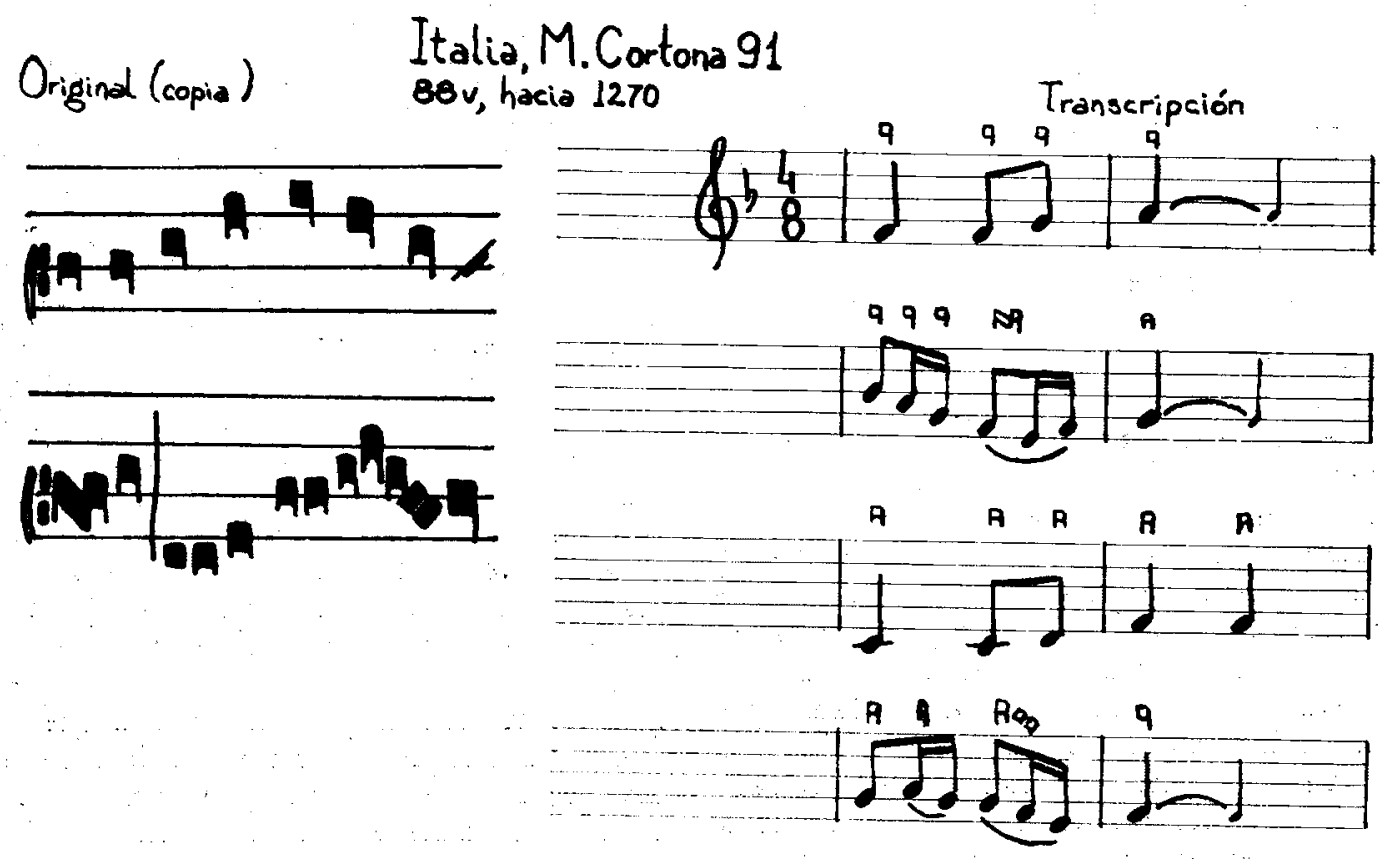

Original. (Copia del manuscrito.) En el códice la notación se manifiesta en dos pautas largas. Como la distancia entre las notas está determinada por el ancho de las sílabas, nosotros hemos acortado las líneas, por razones de espacio; reduciendo los blan- 
cos intermedios, sin que esto importe nada. Las figuras cuadradas con uno o dos trazos son "puntos" de un sonido sin valor escrito; los que tienen la cabeza redonda (véase la antepenúltima) son plicas, y dan un segundo sonido a diestra. Tampoco importan los trazos en este códice, pues apenas son guias laterales para hacer los cuadrados y están semiborrados por los siglos.

Transcripción. Establecida la forma (4x8) y la tonalidad (Fa), ensayamos el agrupamiento de las notas en pies y de los pies en dipodias de movimiento y de reposo en alternancia. Pasamos todos los signos a los pentagramas modernos sin modificar nada de nada. Ponemos en claro el bemol ausente. Atribuímos valor a las figuras de acuerdo con nuestro método especial para este subsistema de notación. Las notas finales se prolongan por la regla de "mora ultimae vocis"; los amanuenses no usan ningún signo para tales prolongaciones en ninguno de los sistemas trovadorescos.
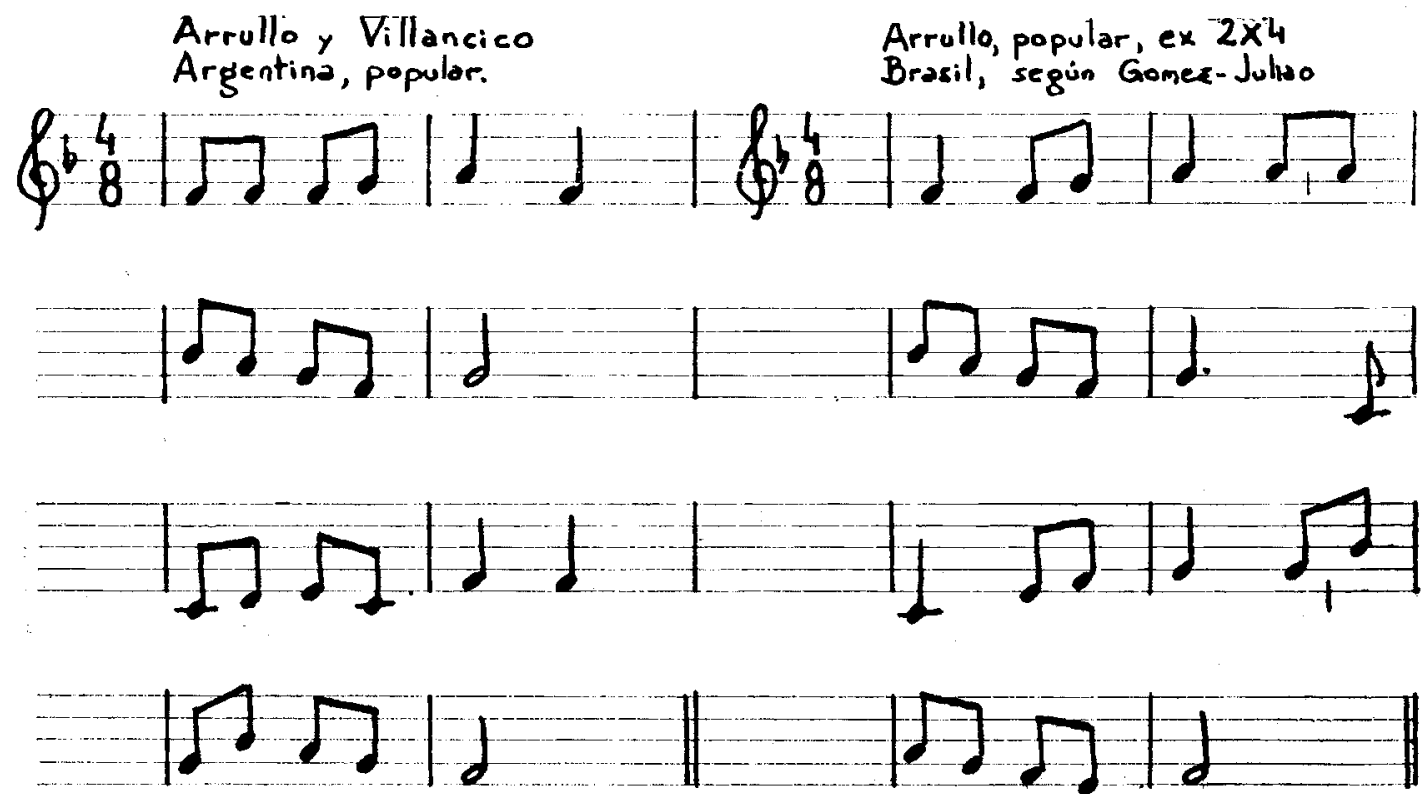

Arrullos folklóricos. La melodía del códice italiano de hacia 1270 reaparece en los campos del Brasil y de la Argentina a setecientos años y a cerca de 10.000 kilómetros. La semejanza de las versiones, superando los términos generales de la analogía estilistica, desciende hasta la minucia particular de tal modo, que hasta nos parece una exageración, casi una falta de respeto al tiempo y al espacio. Lea el estudioso esa escritura medieval de cualquier manera, como pueda; eso que lee está en la campaña de Sudamérica y en muchas otras partes, y hasta se nos presenta en notaciones medidas posteriores a las medievales. Ya ni siquiera importa añadir que, tanto la antigua "lauda" como los arrullos (que son también villancicos de Navidad) tienen textos religiosos. Los villancicos se convierten en arrullos a través de la palabra "niño".

Entre miles y miles de melodías antiguas, entre miles y miles de melodías fol- klóricas americanas, nosotros hemos reconocido esas tres y las hemos puesto en relación. En dos de ellas no ocurre nada; en la primera ocurre simplemente que está escrita en notación hasta hoy ilegible. Sólo quien puede leer los manuscritos medie. vales está en condiciones de relacionarlas.

Una de las bases de nuestro trabajo es la evidencia de que el compositor, como el poeta, utiliza un corto número de formas. Esto mismo podría sugerir a los escépticos que una canción de sólo cuatro frases breves podría crearse de nuevo por azar. Olvidemos la polémica "divergenciaconvergencia" de hace medio siglo; olvidemos el pronunciamiento de preclaros colegas en el sentido de que una canción es fenómeno tan complejo que aleja la idea de la invención independiente; olvidemos que aquí no se trata de una sola canción que se repite sino de gran cantidad de música - cancioneros ențeros de estilos diferentes-; olvidemos que la música folklórica encuentra sus antepasados y que la música 
medieval recobra sus descendientes; en fin, olvidemos la evidencia a título de concesión y digamos que sí, que una cancioncita puede crearse de nuevo.

Podríamos ofrecer a modo de refuerzo varios otros cancioneros folklóricos euro-

_. . . Italia,Cortona 91.f:-70 ... . . . . .
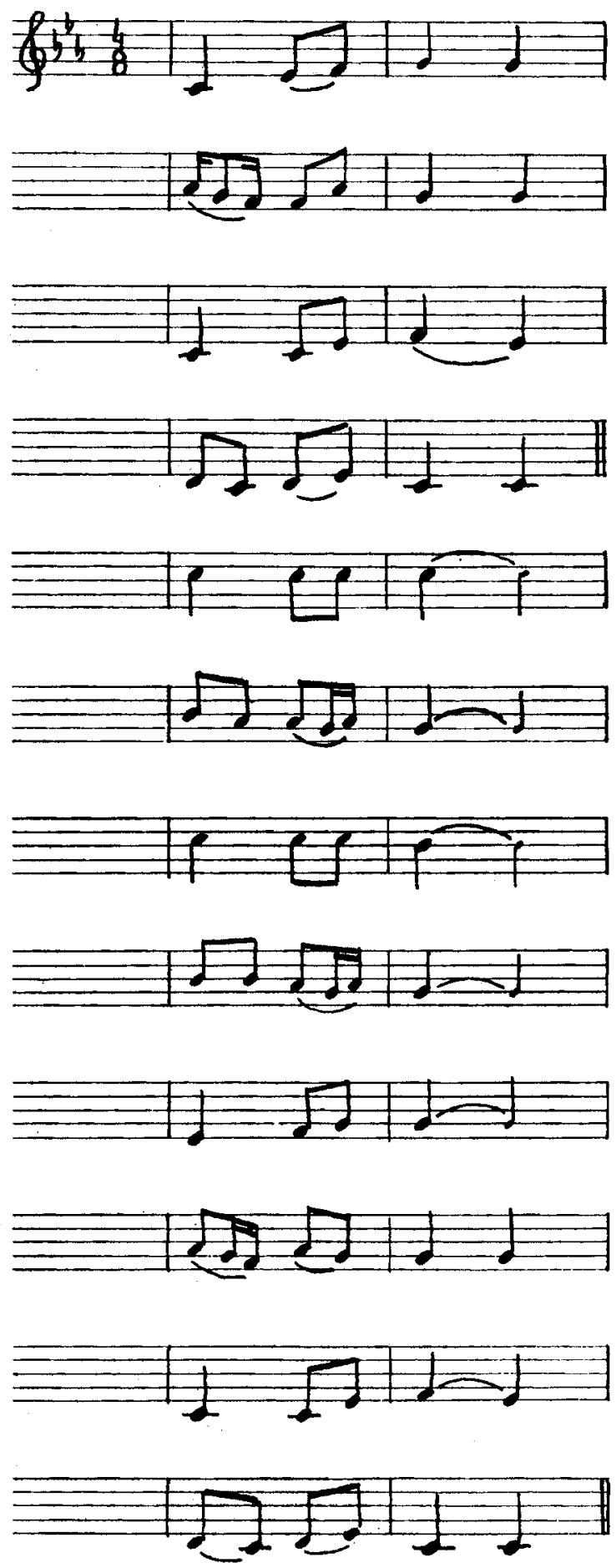

peos que también vegetan sin antepasados; pero nos vamos a limitar a presentar una canción más larga, de dos períodos, es decir, una canción que de ningún modo puede crearse por segunda vez. Nada más que eso. Observemos el paralelo.

Hatikvah, Himno Nacional Hebreo

"25 Canciones hebreas", Ricordi. NN9
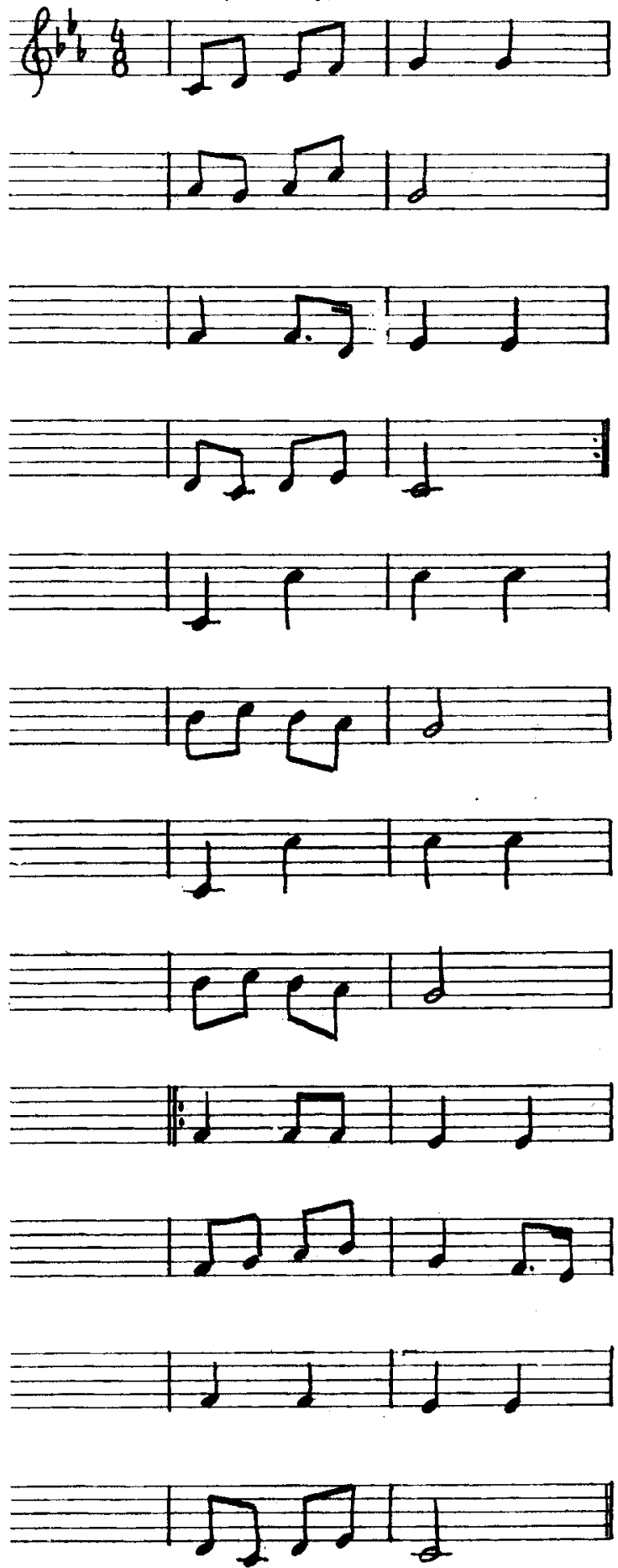
El autor desea hacer una sola aclaración: no conocía el himno hebreo. Un día que lo visitaba el eminente organista belga Julio Perceval se lo dio a leer, y fue él quien reconoció en la versión medieval el remoto antepasado del himno. En el códice de Cortona es un canto cristiano. No más comentarios.

Ha ocurrido lo que debía ocurrir. La música profana de los siglos XII y XIII no constituía un ciclo cerrado; es una de las tantas generaciones históricas que se encadena con música progenitora anterior ignorada pero cierta y con la música posterior que por diversos caminos lucha hasta nuestros días por seguir viviendo.

Pero la revelación de las 5.000 melodías seglares (sin contar las repetidas) que se han conservado en los preciosos códices europeos supera con mucho el simple episodio de una relación entre Europa medieval y Sudamérica folklórica y constituye un nuevo corpus documental capaz de alentar una historia integral de la música de Occidente, camino de una intelección general.

La historia de la música, tal como nos la presentan los historiadores modernos (no los musicólogos), sigue siendo la antigua historia de los príncipes: una historia de los cuatro últimos siglos principalmente atenta a los compositores y a la orquesta. Limitada a la música superior -la más valiosa y menos colectiva- se circunscribe de hecho al $5 \%$ de la música que suena en el mundo.

Al lado de esa música histórica superior vienen deslizándose desde hace siglos en la penumbra varios enormes raudales sonoros para la canción y la danza, la "mesomúsica". Representan cerca del $80 \%$ de la música que se oye actualmente y es tal su importancia económica que promueven y sostienen empresas grabadoras, empresas editoras, enipresas radiotelefónicas y de $\mathrm{TV}$, academias populares, bailes públicos, teatros, fábricas de grabadores y reproductores mecánicos, organizaciones autorales, etc., y extienden sus beneficios, aún sin proponérselo, incluso a la propia música superior.

Por su parte y en sus campos vegeta la música folklórica, segunda en importancia social; y en los más lejanos y retardados hontanares, la ya menguada música de los primitivos se anima y conserva hasta hoy impresionantes datos inéditos sobre orígenes e itinerarios aptos para esbozar una prehistoria musical de hacia doscientos mil años rumbo a los tiempos oscuros en que el hombre, mamífero y desnudo, se hace músico haciendo música.

Las escuelas musicales no gregorianas de los siglos XII y XIII, dignificadas e ilustradas por los príncipes creadores, acogen las tradiciones seglares cultas y parte de las populares en dilatadas áreas europeas $y$, anotadas sus expresiones por orden de la corte, forman hoy, en un ensayo de cuadro sinóptico universal, una especie de friso a la altura de los años 1100-1300 que -como hemos dicho- nos explica el paso de tradiciones arcaicas y nos revela el fundamento de setecientos años de música occidental posterior, activa en los salones o en el afloramiento folklórico.

Octubre, 1962. 